\title{
Large Measles Outbreak in a Religious Community in British Columbia
}

\section{Paul G. Van Buynder}

Fraser Health Authority, Surrey, British Columbia, Canada

*Corresponding author: Fraser Health Authority, Surrey, British Columbia, Canada, Tel: 604-587-4600; E-mail: pjvb@iinet.net.au

Received date: 22 July 2014; Accepted date: 24 Aug 2014; Published date: 29 Aug 2014

Copyright: ( 2014 Van Buynder PG. This is an open-access article distributed under the terms of the Creative Commons Attribution License, which permits unrestricted use, distribution, and reproduction in any medium, provided the original author and source are credited.

\section{Summary}

In March 2014 an outbreak of measles commenced in a small religious school attended by around 350 children from families with extremely low MMR vaccination uptake. Within 4 weeks almost 400 cases were observed within the 1200 member congregation. Only four cases occurred unlinked to the congregation. While importations of measles into Canada are expected and rapid spread is possible in unimmunized communities, public health measures can control outbreaks.

\section{Outbreak Description}

In early March 2014, Public Health officials in the Fraser East area of the Canadian province of British Columbia, were notified by the school principal of several measles cases in a school linked to a protestant Reformed Church of North America (RCNA). The students in the school were known to have historically low immunization coverage rates $(<5 \%$ for measles vaccine) in line with the pastors denominational view that immunization interfered with Gods providence. Over the next 4 weeks 392 cases were identified in the area with all but four cases linked to the religious congregation. Five further cases were identified in a single family from Washington State in the USA; the index child in this cluster also attended the affected school.

\section{Case Definition}

Laboratory confirmation was based on the detection of measles virus RNA by polymerase chain reaction from nasopharyngeal and/or throat swabs or urine, or by measles specific IgM serology in persons with a compatible illness and no recent history of immunization with measles containing vaccine.

Clinically confirmed cases were those linked to a laboratory confirmed case with clinical measles symptoms of fever, cough, coryza or conjunctivitis and a generalized maculopapular rash for at least 3 days. In view of the contained nature of the community, clinical cases with a link to other epidemiological cases were also classified as cases. In many families all siblings developed measles infection.

Of the 392 cases, 388 (99\%) were members of the orthodox protestant community and unvaccinated. Only four unlinked general community cases were identified; one case involved an unvaccinated child and only one was known to have received two vaccine doses. The median age of cases was 10 years and 341 cases $(87 \%)$ were aged from 1-19 years. Six children were aged under one year and only one case occurred in a pregnant female reflecting high levels of immunity in older community residents likely the result of a 1990 measles outbreak (Table 1). The age specific attack rates based on the area population are shown in Table 2. About one third of the estimated 1200 community members developed measles in the first four weeks. Under-reporting of cases within the community is probable outside the school age cohort. However, the families centred follow up likely identified most cases unlike outbreaks in other religious clusters where reporting rates were estimated to be as low as $9 \%$ [1].

\begin{tabular}{|l|l|l|l|l|}
\hline AGE & $\begin{array}{l}\text { Laboratory } \\
\text { confirmed } \\
\text { (not NAR)1 }\end{array}$ & $\begin{array}{l}\text { Epidemiologic link } \\
\text { to lab confirmed } \\
\text { (not NAR) }\end{array}$ & $\begin{array}{l}\text { Epidemiologic } \\
\text { linked to other } \\
\text { NAR2 }\end{array}$ & Total \\
\hline$<1$ & 1 & & 5 & 6 \\
\hline $1-4$ & 4 & 11 & 49 & 64 \\
\hline $5-9$ & 6 & 106 & 5 & 117 \\
\hline $10-19$ & $11(2)$ & $136(1)$ & 13 & 160 \\
\hline $20-39$ & 6 & 12 & 24 & 42 \\
\hline $40+$ & $1(1)$ & & & 2 \\
\hline Unknown & & 2 & 96 & 392 \\
\hline Total & 29 & 267 & & \\
\hline
\end{tabular}

*Data current as of April 10,2014

1NAR equals North American Reformed

2Not epi linked to lab confirmed case but school resident or close contact of school resident

Table 1: Age Specific breakdown of measles cases.

\begin{tabular}{|l|l|l|l|}
\hline Age & Cases & Population & Attack Rate/100,000 \\
\hline$<1$ & 6 & 12,02 & 499 \\
\hline $1-4$ & 64 & 4,982 & 1285 \\
\hline $5-9$ & 117 & 6,437 & 1818 \\
\hline $10-19$ & 160 & 12,870 & 1243 \\
\hline $20-39$ & 42 & 26,249 & 160 \\
\hline $40+$ & 1 & 56,319 & 1.7 \\
\hline $\begin{array}{l}\text { Total } \\
\text { *Population data: BC Stats, P.E.O.P.L.E. 2014 projections for Chilliwack, } \\
\text { Agassiz and Hope }\end{array}$ & 108,059 & 363 \\
\hline
\end{tabular}

Table 2: Age specific attack rates Fraser outbreak region.

The reported cases by onset date of exanthema are shown in the curve at figure 1 and the geographic distributions of cases are shown in Figure 2 . 
Page 2 of 3

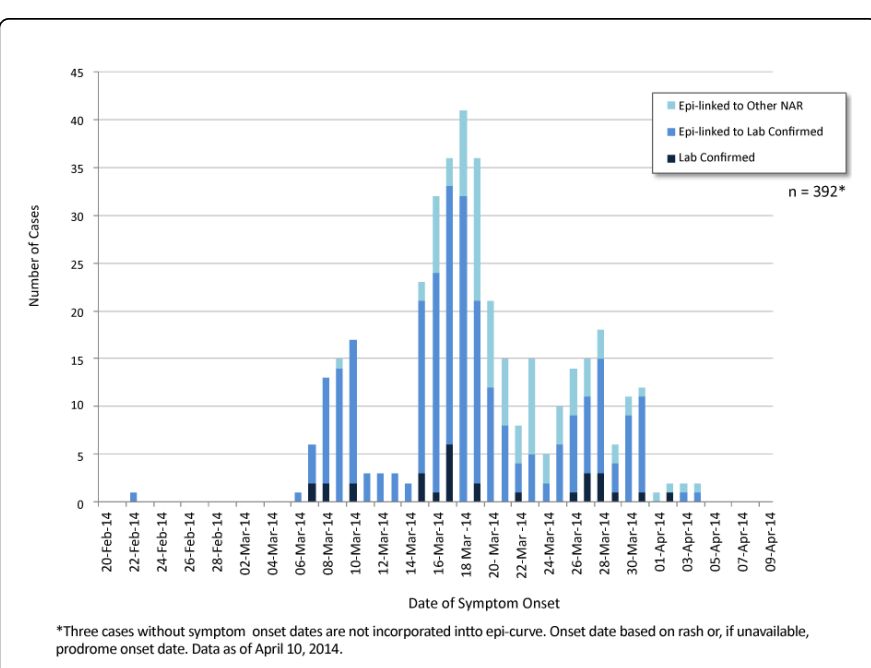

Figure 1: Epidemic curve of reported measles cases by date of symptom onset.

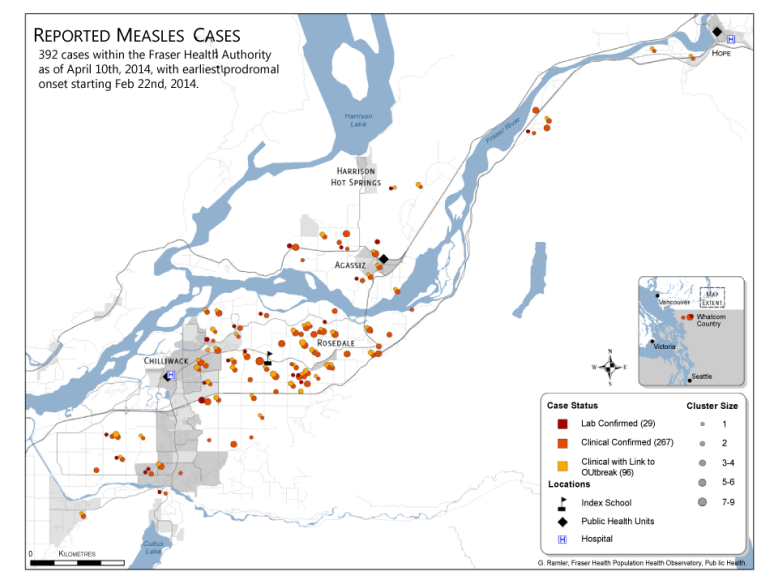

Figure 2: Reported measles cases.

Only four cases were hospitalized; one with neurological complications. There were many anecdotal stories of children with pneumonia and convulsions being managed at home. Transmission within health care facilities was not observed although clinically suspect patients were discouraged from attending for testing unless very ill. Additionally, proof of measles immunity is required for all health care workers (HCW) in the affected area with HCW measles vaccine coverage over $90 \%$.

\section{Laboratory Confirmation and Genotyping}

Of 29 laboratory confirmed cases, 22 were genotyped and all were genotype D8 with the same sequence (MVs/Taunton, GBR/27.12). This sequence was also associated with an importation from the Netherlands in neighbouring Alberta in 2013. The specific D8 sequence associated with this outbreak has also been identified in other international outbreaks.

\section{Background}

The Canadian National Advisory Committee on Immunization currently recommends two doses of measles-containing vaccine; one dose at 12 months of age and one dose at 18 months of age or 4 to 6 years [2]. In British Columbia, the recommendation is for the second dose at kindergarten entry (4 to 6 years) [3]. Kindergarten two dose coverage estimates range from $70 \%$ to over $95 \%$ in the affected area. However, the affected religious community declines immunization and the index outbreak school is reported to have less than $5 \%$ measles immunization coverage.

In Canada, endemic measles transmission has been eliminated. However, sporadic imported cases continue to occur. Secondary spread from these imported cases is usually self-limited and mainly involves individuals who are unimmunized or under-immunized against measles although a large outbreak involving almost 700 cases occurred in Quebec in 2011 [4].

Based on the measles genotype and travel links of community members, the outbreak likely originated in the Netherlands. Two cases did report travelling to the Netherlands although the primary case was not specifically identified. The Netherlands is currently the site of a large outbreak, within a vaccine-refusing religious community, which has links to the religious community affected here in British Columbia. More than 2,600 cases have been reported in the Netherlands, with 182 hospitalizations $[5,6]$.

\section{Control Measures}

There are no treatments that kill the measles virus. Treatment aims to ease symptoms until the body's immune system clears the infection. For most cases, rest and simple measures to reduce a fever are all that are needed for a full recovery. Symptoms will usually disappear within 7-10 days.

Control measures were focused on intensive case finding using the school attendance lists as a basis to identify cases and follow up of families by phone. Contacts were offered vaccine or immunoglobulin if recently exposed. Effectiveness of intramuscular immunoglobulin was disappointing. One high risk, immunocompromised contact was successfully protected by a repeated high dose intravenous immunoglobulin regime in immunocompromised contacts. Immunization clinics for the public were established in at-risk areas. Cases were advised to self-isolate, and avoid laboratory testing in hospital (to mitigate the risk of hospital-based exposure). The school was closed early for spring break and remained closed for 3 weeks after which only those children (over $60 \%$ of the school) with documented 5 days of rash were allowed back to return to school.

Susceptible contacts of cases (suspect, clinical, or confirmed) were advised to remain quarantined at home under self-quarantine for 21 days from their most recent exposure and this was supported by church leaders. A school trip to Haiti was cancelled and a planned Mexico trip restricted to those known to be immune.

As the community was vaccine refusing no change to scheduling was introduced and vaccine was not offered to infants 6-11 months of age. Second dose vaccine was offered early to surrounding community members. Some community members accepted Immunoglobulin and an occasional contact accepted vaccine. 
Citation: Van Buynder PG (2014) Large Measles Outbreak in a Religious Community in British Columbia. J Vaccines Vaccin 5: 246. doi: 10.4172/2157-7560.1000246

Page 3 of 3

\section{Discussion}

Although measles is considered eliminated in North America, in 2014 cases have been reported in 2014 in five Canadian provinces: British Columbia, Alberta, Saskatchewan, Manitoba and Ontario prompting a Public Health Agency of Canada measles alert about cases related to travel to countries where measles is endemic or where there are large outbreaks, such as the Philippines and the Netherlands. 56 Similar concerns were expressed by the United States CDC after the 2014 measles case count reached 288 in May, the highest in 20 years [7].

Fraser Health has previously seen sporadic measles cases in religious groups often in the context of anecdotal reports with the suggestion of substantial under-reporting. In 1999-2000, a measles epidemic occurred in The Netherlands, with 3292 reported cases; 94\% of the affected patients had not been vaccinated. Three patients died, and $16 \%$ had complications. 1 A sero-survey of the current affected community during this outbreak coupled with low attack rates in those over 20 years of age suggest that many community residents were infected at that time.

This is the largest measles outbreak in British Columbia in 30 years. The most recent substantial Canadian outbreak occurred in Quebec in 2011 where a single super-spreading event led to 678 cases in a school and surrounding areas [4]. Quebec documented significant failure of two dose vaccine regimes within the cluster 4 and postulated a need to delay the 12 month MMR vaccine dose until later in infancy to improve vaccine effectiveness [8].

Control measures in our cluster were aided by community support for self-isolation and the fact that some families lived on distinct small acreage settings on the edge of the town. Despite the large outbreak in this unimmunized religious community, there was very limited spread to the general community. This suggests that two dose regimes with the first dose at 12 months coupled with aggressive isolation can limit measles transmission even during large measles outbreaks in unimmunized communities.

\section{Acknowledgements}

The authors thank the public health staff involved in outbreak control and the church leaders who supported control measures.

\section{References}

1. van den Hof S, Conyn-van Spaendonck MAE, van Steenbergen JE (2002) Measles epidemic in the Netherlands, 186: 1483-1486.

2. Public Health Agency of Canada (2010) Statement on Measles-MumpsRubella-Varicella Vaccine. National Advisory Committee on Immunization (NACI). Canada Communicable Disease Report; 36.

3. British Columbia Center for Disease Control. Measles Vaccine.

4. De Serres G, Markowski F, Toth E, Landry M, Auger D et al. (2013) Largest Measles Epidemic in North America in a Decade-Quebec, Canada, 2011: Contribution of Susceptibility, Serendipity, and Superspreading Events. J Infect Dis. 207: 990-998.

5. Knoi MJ, Urbanus AT, Swart EM, Mollema 1, Ruijs WL et al (2013). Large ongoing measles outbreak in a religious community in the Netherlands. Euro Surveill. 18: 20580.

6. Public Health Agency of Canada. Public health notice: Measles.

7. Gastañaduy PA, Redd SB, Fiebelkorn AP, Rota JS, Rota PA et al. (2014) Measles-United States 63: 1-4.

8. De Serres G, Boulianne N, Defay F, Brousseau N, Benoît M, et al. (2012) Higher risk of measles when the first dose of a 2-dose schedule of measles vaccine is given at 12-14 months versus 15 months of age. Clin Infect Dis. 55: $394-402$. 